\title{
The public health implications of assisted reproductive technologies
}

\author{
R. Deonandan, $\mathrm{PhD}(1)$
}

\begin{abstract}
Objective: The public health implications of Assisted Reproductive Technologies (ART) are largely unknown by researchers and policy makers alike. Outcomes need to be considered, not just as clinical issues, but in terms of effect on public health.

Methods: Using a qualitative key informant process involving interviews with selected professionals and a review of the medical literature, eight general themes of public health issues associated with ART were identified, and are discussed.

Recommendations: Short and long-term health outcomes of women undergoing ART procedures, and of their offspring, need to be considered, as do the epidemiological risks associated with donated gametes and the effect on health services of multiple and preterm births, both produced in higher rates by ART. A national surveillance system and greater inter-jurisdictional communication are important strategies for addressing these evolving concerns.
\end{abstract}

Keywords: public health, reproductive medicine, review literature, infant, IVF, ART, in vitro fertilization

\section{Introduction}

In 2004, the parliament of Canada enacted the Assisted Human Reproduction Act to provide health and safety oversight of assisted reproduction procedures, which the Act defines as controlled technological activities performed for the purpose of creating a human being, specifically in vitro fertilization (IVF), its related technologies, such as intracytoplasmic sperm injection (ICSI), and activities relating to the handling of gametes and embryos. ${ }^{1}$ In the arena of public discourse, issues concerning assisted reproductive technologies (ART) tend to be contextualized in terms of specific clinical outcomes; ethical concerns regarding, among other things, the extension of fertility into old age; and the rapid commercialization of the sector, resulting in evolving relationships between government, commercial medical practices and various public health insurance models. Less discussed, but no less important, are the public health implications of ART.

In Canada, ART remains among the few categories of medicine that exists outside many of the provincial public health insurance systems. Most ART services are provided by commercial clinics that deal directly with patients. This is particularly true for the more advanced ART procedures such as ICSI and embryo cryopreservation. As a result, discussions about the effects and societal role of ART are more commonly replaced by the more politically sanguine topics of business management and the role of health insurance.

ART, and in particular IVF, exists within a delicate sociopolitical context along with eugenic philosophies, gender selection, congenital screening, equity and access. These are issues with a far greater societal reach that transcend the intimate relationship between the ART patient and practitioner, and extend into the mandate of government.

\section{Objectives}

The objectives of this study are to explore the population health implications of the growing group of medical interventions that constitute ART. The goal is to enumerate potential and observed beneficial and potentially deleterious public health effects of ART on Canadian society, and to suggest ways of ameliorating the negative effects. The intent is to introduce and explore ART as an area of potential policy interest, rather than conduct an exhaustive systematic review of the evidence surrounding ART and public health.

\section{Methods}

Public health issues associated with ART were identified using two methods: (1) a qualitative key informant process involving input from the author and other selected professionals, who were questioned through one-on-one unstructured interviews; and (2) a parallel review of medical literature from the National 
Library of Medicine's PubMed* database, using the following search terms: public health, assisted reproduction, artificial reproduction, in vitro fertilization and its initialism IVF, and intracytoplasmic sperm injection and its initialism ICSI. The author paid special attention to topics deemed most relevant to Canada and only examined studies published in English. Once general themes were identified through this dual process, the author undertook a broader Google and PubMed search to find examples of these themes in practice in both peer-reviewed and lay media.

\section{Results}

The research and interviews identified eight general themes of public health issues associated with ART. Four of these themes can be considered outcomes typically expected from ART procedures (general biological outcomes, psychosocial outcomes, multiple pregnancies and births, and premature births), a fifth theme concerns ICSI, and three additional themes are neither ART outcomes nor procedures but concepts of public health concern (gametes as disease vectors, consanguinity and cross-border reproductive care). Lastly, both the key informants and the literature noted that ART may present many positive public health, demographic and economic impacts, besides those deemed deleterious.

\section{Discussion}

\section{General biological outcomes}

The most obvious impact on public health is the as yet poorly understood long-term outcomes associated with various ART procedures. Some outcomes affect the mother, and others, the child. In a public health context, we must also consider outcomes affecting whole families and their support structures.

IVF, the flagship procedure within the panoply of ART technologies, has been with us for over 30 years; as such, we are now able to assess its long-term effects. Most studies of short-term biological outcomes suggest that congenital malformations and aberrations, childhood cancers, acquired medical conditions, chronic illness, physical growth, and cognitive and socioemotional development are within the expected range for naturally conceived pregnancies. ${ }^{2}$ Comprehensive studies looking at effects beyond early childhood are few, largely due to difficulties with data linkage and long-term longitudinal follow-up. One attempt to perform such a linkage concluded that "long-term morbidity among children conceived by IVF is higher than among naturally conceived infants." ${ }^{3}$ In what is a recurring theme in the literature examining morbidities associated with ART, Kallen et al. suggest that the elevated risk of morbidity has much to do with the tendency of ART to produce multiple and preterm births. ${ }^{3}$

\section{Psychosocial outcomes}

Some studies suggest that the mothers of ART-conceived children view their offspring as more vulnerable, see themselves as less competent, have higher levels of anxiety about parenting and less satisfaction with family functioning. ${ }^{4-6}$ Moreover, the parents of these children may have lower self-esteem and marital satisfaction. ${ }^{6,7}$ Several studies have found that ART-conceived children are more temperamental as babies, have more negative behaviours in response to stress, have more behavioural problems and adjust more poorly at school, and are more aggressive, anxious and depressed. ${ }^{4,7,8,9} \mathrm{~A}$ recent cross-sectional evaluation of the first cohort of IVF-conceived young adults in the USA found that psychological health problems were preponderant. ${ }^{10}$ Depending upon the extent of these effects, as ART becomes more widely used, these trends will affect a variety of our institutions, particularly public education and public health.

A dimension of psychosocial health associated with ART that is underrepresented in the literature is the negative emotional impact on patients who fail to produce a child, even after lengthy, invasive and expensive ART treatments. Since the IVF failure rate outstrips the success rate, ${ }^{11}$ the management of expectations must be a priority. Ironically, it seems that women with high anticipatory anxiety may also have lower pregnancy rates ${ }^{12}$ and, not surprisingly, women undergoing IVF show much higher levels of anxiety than do those in the general population. ${ }^{13}$ Moreover, at least one study suggests that among women undergoing IVF, it is the experience of receiving a negative pregnancy test that is the greatest predictor of depression. ${ }^{14}$

As our population ages and the demand for ART services increases, the mental health profile of our community will also change. Our public mental health system must be able to respond to this change.

More immediate public health concerns for parents undergoing ART interventions are the adverse effects associated with fertility drugs, including the reported association with an increased risk of breast, uterine and ovarian cancer. Though these associations have not been proven, ${ }^{15}$ since older women tend to be the ones seeking ART services, there is some concern that health risks associated with ageing (such as certain cancers) may still be exacerbated by the hormonealtering effects of fertility drugs. ${ }^{15,16}$

Despite the evidence to the contrary described earlier, the overall evidence suggests that ART-conceived children are not psychosocially significantly different from naturally conceived children. It seems that preexisting "personality factors" that are already present in the family seeking ART are more important predictors of psychosocial issues reflected by an ART-conceived child than are any treatment-related factors. ${ }^{17}$

\section{Multiple pregnancies and multiple births}

Perhaps the single most important impact of ART remains the high rate of multiple pregnancy: about a fifth to a third of all ART pregnancies are twins, who outnumber ART triplets and higher order multiples by a factor of between four and ten. ${ }^{18,19}$ Multifetal gestations face greater problems than singletons at every stage of pregnancy and labour; each additional fetus leads to curtailment of both fetal growth and the duration of gestation, two of the most

\footnotetext{
*http://www.ncbi.nlm.nih.gov/pubmed
} 
important predictors of fetal and neonatal health. ${ }^{20}$

Twins are at an increased risk for cerebral palsy, developmental delay, learning disability, sensory impairment, language delay, and attention and behavioural problems. ${ }^{21}$ The cerebral palsy rate for triplets is 47 times that of singletons. ${ }^{22}$ Overall, 1 in 10 women pregnant with twins and 1 in 5 women pregnant with triplets, regardless of mode of conception, who reach 20 weeks of gestation, will experience at least one of the following: a stillbirth, an infant death or a child with cerebral palsy. ${ }^{22}$ A recent review of the literature concluded that there does appear to be an association of ART with a heightened risk of cerebral palsy, owing, it is suggested, to ART's tendency to produce preterm births. ${ }^{23}$

These effects constitute a burden on the public health of a community, both in terms of their direct health costs, and in terms of their effect on the psychosocial and economic well-being of the parents. Indeed, families with children afflicted with cerebral palsy face an increased chance of marital breakdown. ${ }^{24}$ The impact on a community, in terms of service demand and overall cost, are difficult to quantify.

However, any association between IVF and cognitive impairment or development issues may be confounded by intervening technologies. For instance, a Danish study of 957 singletons born after frozen embryo implantation found that using frozen embryos resulted in a lesser chance of cerebral palsy than using fresh embryos, but still presented a higher risk than in the non-ART group. ${ }^{25}$

Many patients undergoing ART may see a multiple pregnancy as a positive outcome, as it represents an increased chance of producing a live child. But it also represents an increased chance of producing a multiple birth which, as has been discussed, is susceptible to a host of deleterious consequences. Indeed, in instances of co-twin death in pregnancies of over 20 weeks, there is an eight-fold increase in the risk of cerebral palsy for the surviving twin compared with the risk for twins when both survive. ${ }^{22}$ As such, we need a more robust counselling strategy to better manage expectations and offer a more thorough patient education package. ${ }^{26}$

A 2008 review of published evidence surrounding the long-term health of ARTconceived children concluded that "the main risks for the future well-being of ART children remain multiple pregnancies and low birth weight. Evidence regarding the outcome of singletons born at term following ART is generally reassuring." ${ }^{27}$

\section{Premature births}

There is strong evidence that IVF is associated with an increased chance of both preterm birth and low birth weight (LBW), often in association with multiple pregnancies and multiple births. In 2003, Tough et al. found that IVF accounted for $17.8 \%$ of the rise in LBW and $10.5 \%$ of the rise in preterm birth rates in 1994-96 in Alberta. ${ }^{28}$ Note that preterm birth has been identified as one of the most important perinatal health problems in industrialized nations, ${ }^{29}$ typically accounting for $75 \%$ to $85 \%$ of all perinatal mortality (stillbirths plus deaths to infants less than 7 days old) in Canada. ${ }^{30,31}$ And, as mentioned above, the increased risk of preterm birth may explain the observed increased risk in cerebral palsy. ${ }^{23}$

The extent to which ART contributes to the heightened mortality and morbidity rates among infants and to the economic costs of caring for preterm deliveries needs to be considered when formulating the public health profile of a community. Factors such as an increased demand for neonatal care services, despite a national reduction in birth rate, may be pertinent to policy makers.

\section{Intracytoplasmic sperm injection}

ICSI is a procedure that in many ways bypasses natural selection by forcing the union of gametes that are otherwise biologically impeded from fertilizing. In 1995, In't Veld et al. suggested that there may be an increased risk of fetal sex chromosome anomalies following ICSI conception. ${ }^{32}$ Seven years later, another study found that, of 1437 ICSI-conceived fetuses, 2.9\% had chromosomal anomalies; 33 other studies since have found similar and slightly higher rates, such as a Belgian review of ICSI cycles between 1994 and 2000, which reported a total malformation rate of $6.5 \% .^{34}$ Kurinczuk argued that ICSI enables the inheritance of y-chromosome linked microdeletions, ${ }^{26}$ thus increasing the population prevalence of otherwise rare genetic disorders; however, there is a comparatively low risk of y-linked inheritance of abnormalities. It is possible that the more subtle of these disorders will not emerge until well into adolescence, and are thus presently unnoticeable.

The role of ICSI as a treatment for malefactor infertility, in coordination with IVF, makes it both important and prevalent among ART services. To better gauge its public health implications, longer term longitudinal studies need to be undertaken to identify and quantify putative adverse effects into adolescence and young adulthood.

\section{Gametes as disease vectors}

A public health issue that is unlikely to present a crisis, but nonetheless deserves attention, is the risk of infectious disease transmission via donated gametes. Fertility clinics diligently test all reproductive fluids for major infections such as HIV, and disease testing for sperm and other donated tissues in Canada is quite robust. But given that no test is $100 \%$ effective, and that a typical testing panel will only cover the most likely infections, it is possible that sperm banks, for instance, could act like disease vectors.

The risk is not restricted to infectious disease: inherited diseases, such as hypertropic cardiomyopathy, can be transmitted through the gamete donation process. ${ }^{35}$ In 2007, the Los Angeles Times reported on an American woman who had donated her eggs to at least four infertile couples, only to learn later that she was a carrier of the gene for Tay-Sachs disease. At least one of the offspring generated from her donations has the disease, which is typically fatal. ${ }^{36}$ Her case illustrates the potential for gamete donation to blossom into unforeseen public health challenges, and the need for both superior disease screening and donation tracking, through either a donor registry or large-scale surveillance system.

While it is true that natural conception (i.e. unprotected sexual intercourse) presents 
risks of disease transmission of greater overall relevance to Canadian public health needs, gamete donation represents a unique disease vector modality that may need to be considered within the scope of public health policy by virtue of its ability to produce clusters of offspring in the scores and potentially hundreds.

\section{Consanguinity}

A related risk is the potential for offspring produced from gametes from the same donor, unaware of their genetic bonds, to create a family together. The public health implications are obvious, as offspring of consanguine unions have greater risk for a host of inherited ailments. Given the dearth of sperm donors in Canada, and thus the wide spread of each donor's genetic material, this risk may not be as small as would otherwise be expected. For example, the media reported on one such donor in 2007, a man who may have as many as 50 children in the United States alone. ${ }^{37}$

Possible strategies for mitigating the risk of consanguinity include surveillance of donation clusters, better access by offspring to their status as products of donation, and the conscious limiting of the number of offspring permissible per donor.

\section{Cross-border reproductive care}

An emerging issue with respect to ART is the trend of infertile couples to seek services beyond their countries of residence. Couples typically use "cross-border reproductive care" or "reproductive tourism" either to obtain the services they require more cheaply abroad, or because these services are not offered in their home country. A caveat to the latter reason is that often cross-border services are sought to bypass legal restrictions at home, for example, to acquire a paid surrogate mother, to buy sperm from a paid donor or to select the sex of one's child-all illegal in Canada.

The public health implications of seeking cross-border care are manifold, but can be reduced to two requirements: the need to protect such couples from poor quality services abroad, and the need to protect disadvantaged individuals from being exploited for their reproductive tissues or capabilities. An international effort is needed to put in place ethical and health and safety guidelines for the management of cross-border care and the avoidance of undue suffering or exploitation.

While most regard the phenomenon of cross-border reproductive care as involving the movement of people (those seeking care or those providing services, such as surrogate mothers or gamete donors), a separate category involves the movement of reproductive tissues, such as gametes and embryos. The concerns in this case involve the inability to ensure that procedures for the extraction, creation, preservation, transportation and sharing of these tissues meet the standards set within Canadian borders. Efforts to itemize and monitor quality control indicators may help assuage such concerns.

\section{Positive public health impacts}

ART presents us with several positive societal outcomes: first and foremost, of course, is the potential to treat the chronic disease of infertility, and hence benefit from the positive psychosocial effects of successful treatment.

Additionally, in some circles the West's declining birth rate is considered a demographic crisis, threatening to reduce our tax base and cultural longevity; ART represents an avenue to quell that trend. Older individuals' ability to conceive has also effectively lengthened the available time for education, self-exploration and unfettered economic activity, arguably resulting in improved and more productive human capital. Older, childless couples also typically enjoy higher standards of living, and are thus better able to afford the resources for caring for a child that they produce through ART.

Of possibly significant demographic relevance is the Rand Corporation finding that "an IVF-conceived child, average in every respect (for example, future earnings, healthcare consumption, and life expectancy), represents a net positive [financial] return to the government." ${ }^{38}$ In other words, the application of ART may ultimately result in economic advantages to certain societies, barring any deleterious health characteristics of ART-produced individuals who may represent exceptional costs to the health care system.

\section{Recommendations}

Policy concerning the impacts of ART must be informed by reliable data. Research in this field has been predominantly in the scientific arena, focusing on maximizing the probability of pregnancies and live births and on minimizing invasiveness and cost. Non-clinical research has explored the economic dimensions of IVF and related procedures, well known as costly endeavours that must co-exist with traditional medical care within a socialized medical system. Less common are population health studies exploring the extent of demand of fertility services, and the longterm health consequences of ART interventions for both mother and child.

Clearly, surveillance is the ideal instrument for monitoring a variety of important factors associated with ART-related public health, including donated gametes as disease vectors, potential consanguinity, deleterious short-term health consequences for women undergoing ART procedures, deleterious long-term impacts on both mothers and offspring, and longitudinal factors related to infertility, such as whether infertility can (ironically) be passed on from parent to child. Surveillance would also provide data important for long-term social planning, as it provides a basis for estimating demographic change resulting from ART-generated modifications to population birth rates and health service demands.

Additional policy directions may include limiting the number of offspring that can be produced from a single gamete donor, thus controlling for the risk of inadvertent consanguine couplings and, again, better surveillance of gamete usage and the risk factors of donors. For the improved safety and quality control of cross-border reproductive care, international cooperation is required to both determine the true extent of the phenomenon and to establish universally acceptable standards of care, both clinically and socially. This, too, would be helped by improved surveillance of the use of ART. 
The pursuit of an ART surveillance strategy in any nation is a large undertaking. In Canada, it is complicated by federalprovincial jurisdictional issues, data compatibility issues, anonymity/confidentiality concerns, migratory forces and the specific nature of ART as a privately funded endeavour within a publicly funded socialized medicine milieu. But progress down this path begins with an appreciation of the importance-from the societal and public health standpoint-of ART, beyond the personal and intimate relationship between patient and doctor.

\section{Conclusion}

As the populations of Canada and similar Western nations age, and the trend of deferring reproduction into the later stages of life continues, the demand for ART services will increase. Short-term biological outcomes of IVF, ICSI and other reproductive technologies have been studied to some extent, but the opportunities for examining long-term outcomes are only now arising. Such outcomes need to be considered, not just as clinical issues, but in terms of public health impacts.

\section{References}

1. Department of Justice Canada. Assisted Human Reproduction Act S.C. 2004, c.2 [Internet]. Ottawa (ON): Department of Justice Canada; 2004 [cited 2010 March 19]. Available from: http://laws.justice. gc.ca/en/A-13.4/FullText.html

2. Yu V. Are there risks in the long term outcome of children born following assisted reproduction technology? J Arab Neonatal Forum. 2005;2:1-4.

3. Kallen B, Finnstrom O, Nygren KG, Olausson PO. In vitro fertilization in Sweden: child morbidity including cancer risk. Fertil Steril. 2005;84:605-10.

4. McMahon CA, Ungerer JA, Beaurepaire J, Tennant C, Saunders D. Psychosocial outcomes for parents and children after in vitro fertilization: a review. J Reprod Infant Psyc. 1997;13:1-16.
5. Gibson FL, Ungerer JA, Tennant CC, Saunders DM. Parental adjustment and attitudes to parenting after in vitro fertilization. Fertil Steril. 2000;73:565-74.

6. Hahn CS, DiPetro JA. In vitro fertilization and the family: quality of parenting, family functioning, and child psychosocial adjustment. Dev Psychol. 2001;37:37-48.

7. Levy-Shiff R, Vakil E, Dimitrovsky L, Abramovitz M, Shahar N, Har-Even D, Gross S, Lerman M, Levy I, Sirota L, Fish B. Medical, cognitive, emotional, and behavioral outcomes in school-age children conceived by in-vitro fertilization. J Clin Child Psychol. 1998;27:320-9.

8. Gibson FL, Ungerer JA, Leslie GI, Saunders DM, Tennant CC. Development, behaviour and temperament: a prospective study of infants conceived through in-vitro fertilisation. Hum Reprod. 1998;13:1727-32.

9. Gibson FL, Ungerer JA, McMahon CA, Leslie GI, Saunders DM. The mother-child relationship following in vitro fertilisation (IVF): infant attachment, responsivity, and maternal sensitivity. J Child Psychol Psychiat. 2000;41:1015-23.

10. Beydoun HA, Sicignano N, Beydoun MA, Matson DO, Bocca S, Stadtmauer L, Oehninger S. A cross-sectional evaluation of the first cohort of young adults conceived by in vitro fertilization in the United States. Fertil Steril [Internet]. 2010 Feb 3 [cited 2010 Mar 19]. Available from: http://www.fertstert. org/article/S0015-0282\%2809\%2904209-5/ abstract

11. Moragianni VA, Penzias AS. Cumulative live-birth rates after assisted reproductive technology. Curr Opin Obstet Gynecol [Internet]. 2010 Mar 6. [Epub ahead of print] Available from: http://www.ncbi. nlm.nih.gov/pubmed/20216414

12. Feichtinger W. Results and complications of IVF therapy. Curr Opin Obstet Gynecol. 1994; 6:190-7.

13. Visser AP, Haan G, Zalmstra H, Wouters I. Psychosocial aspects of in vitro fertilization. J Psychosom Obstet Gynaecol. 1994;15:35-43.
14. Volgsten H, Skoog Svanberg A, Ekselius L, Lundkvist O, Sundstrom Poromaa I. Risk factors for psychiatric disorders in infertile women and men undergoing in vitro fertilization treatment. Fertil Steril. 2010;93:1088-96.

15. British Broadcasting Corporation. Fertility drugs given cancer all-clear [Internet]. London: British Broadcasting Corporation; 2002 July 2 [cited 2010 March 19]. Available from: http://news.bbc.co.uk/1/ hi/health/2079831.stm

16. Jensen A, Sharif H, Kjaer SK. Use of fertility drugs and risk of uterine cancer: results from a large Danish population-based cohort study. Am J Epidemiol [Internet]. 2009 Dec 1;170(11):1408-14. Epub 2009 Nov 1. Available from: http://www.ncbi. nlm.nih.gov/pubmed/19884127

17. Lowyck B, Luyten P, Corveleyn J, D'Hooghe T, Buyse E, Demyttenaere K. Well-being and relationship satisfaction of couples dealing with an in vitro fertilization/intracytoplasmic sperm injection procedure: a multilevel approach on the role of self-criticism, dependency, and romantic attachment. Fertil Steril. 2009;91:387-94.

18. Hurst T, Shafir E, Lancaster P. Assisted conception Australia and New Zealand 1996. Assisted reproduction series no. 3. Sydney (AU): AIHW National Perinatal Statistics Unit, 1997.

19. Schieve LA, Meikle SF, Ferre C, Peterson HB, Jeng G, Wilcox LS. Low and very low birth weight in infants conceived with use of assisted reproductive technology. N Engl J Med. 2002;346:731-7.

20. McKeown T, Record RG. Observations on foetal growth in multiple births in man. J Endocrinol. 1952;8:618-63.

21. Allen MC. Factors affecting developmental outcome. In: Keith LG, Papiernik E, Keith DM, Luke B, editors. Multiple pregnancy, epidemiology, gestation and perinatal outcome. New York: Parthenon Publishing Group; 1995. pp. 599-612. 
22. Petterson B, Nelson KB, Watson L, Stanely F. Twins, triplets, and cerebral palsy in births in Western Australia in the 1980s. BMJ. 1993;307:1239-43.

23. Hvidtjorn D, Schieve L, Schendel D, Jacobsson B, Svaerke C, Thorsen P. Cerebral palsy, autism spectrum disorders, and developmental delay in children born after assisted conception: a systematic review and meta-analysis. Arch Pediatr Adolesc Med. 2009;163:72-83.

24. Joesch JM, Smith KR. Children's health and their mother's risk of divorce or separation. Soc Biol. 1997;44:159-69.

25. Pinborg A, Loft A, Aaris Henningsen AK, Rasmussen S, Nyboe Andersen A. Infant outcome of 957 singletons born after frozen embryo replacement: The Danish National Cohort Study 1995-2006. Fertil Steril [Internet]. 2009 Jul 30 [cited 2010 Mar 19]. Available from: http://www.fertstert.org/article/S00150282\%2809\%2901297-7/abstract

26. Kurinczuk JJ. Safety issues in assisted reproduction technology. From theory to reality-just what are the data telling us about ICSI offspring health and future fertility and should we be concerned? Hum Reprod. 2003;18:925-31.

27. Basatemur E, Sutcliffe A. Follow-up of children born after ART. Placenta. 2008;29 Suppl B:135-40.

28. Tough SC, Newburn-Cook CV, White DE, Fraser-Lee NJ, Faber AJ, Frick C, Svenson LW, Sauve R. Do maternal characteristics and past pregnancy experiences predict preterm delivery among women aged 20 to 34 ? J Obstet Gynaecol Can. 2003;25:656-66.

29. Hertzman C, Weins M. Child development and long-term outcomes: a population health perspective and summary of successful interventions. Soc Sci Med. 1996;43:1083-95.

30. Halperin W, Horan JM. Surveillance of injuries. Public Health Rep. 1998;113:424-6.

31. Chalmers B, Wen SW. Perinatal care in Canada. BMC Womens Health. 2004;4(Suppl 1): S28.
32. In't Veld P, Brandenburg $H$, Verhoeff $A$, Dhont M, Los F. Sex chromosomal abnormalities and intracytoplasmic sperm injection. Lancet. 1995;346:773.

33. Bonduelle $\mathrm{M}$, Liebaers I, Deketelaere V, Derde M-P, Camus M, Devroey P and Van Steirteghem AC. Neonatal data on a cohort of 2889 infants born after ICSI (1991-1999) and of 2995 infants born after IVF (19831999). Hum Reprod. 2002;17:671-94.

34. Hindryckx A, Peeraer K, Debrock S, Legius E, de Zegher F, Francois I, Vanderschueren D, Demyttenaere K, Rijkers A, D’Hooghe T. Has the prevalence of congenital abnormalities after Intracytoplasmic Sperm Injection increased? The Leuven Data 1994-2000 and a review of the literature. Gynecol Obstet Invest. 2010;70:11-22.

35. Maron BJ, Lesser JR, Schiller NB, Harris KM, Brown C, Rehm HL. Implications of hypertrophic cardiomyopathy transmitted by sperm donation. JAMA. 2009 Oct 21;302:1681-4.

36. Heisel W. A donor egg gives life - and a death sentence [Internet]. The Los Angeles Times. 2007 Dec 8 [cited 2010 March 19]. Available from: http://articles.latimes.com/ 2007/dec/08/local/me-eggs8

37. Wolff $\mathrm{J}$. What is a father: the genetic parent [Internet]. Best Life Magazine; 2007 May 16 [cited 2010 March 19]. Available from: http://www.cryobank.com/_resources/pdf/ News/Genetic-Parent.pdf

38. Connolly MP, Pollard MS, Hoorens S, Kaplan BR, Oskowitz SP, Silber SJ. Long-term economic benefits attributed to IVF-conceived Children: a lifetime tax calculation. Am J Manag Care. 2008;14:598-604. 